Forthcoming in American Journal of Bioethics, Neuroscience (http:/ / www.ajobneuroscience.com)

Open peer commentary on John Banja's "Could have chosen otherwise under identical conditions": An Evolutionary

Perspective on Free Will.

\title{
The Embodied and Social Dimensions of Free Will: The Value of Phenomenology
}

\author{
Andreas Elpidorou \\ Department of Philosophy \\ University of Louisville
}

1. John Banja offers an evolutionary account of free will according to which freedom is "a capacity to intend and execute behavior(s) that the organism understands to be in his or her best interests" (12). Thus, what it means to be free is not tantamount to the ability to act otherwise under identical conditions, as libertarian accounts of free will would have it. Rather, organisms, even though antecedently and completely determined by bioevolutionary processes (10), act freely insofar as they act in a way that confers to them an evolutionary advantage. To act freely, Banja holds, is to act smartly. And to act smartly is to act adaptively.

Banja offers his account as a superior alternative to the various extant libertarian formulations of free will. In one of the many places in which he criticizes such understandings of free will, he writes:

The libertarian formulation of free will is not only oblivious to this dynamic and improvised drama between organism and world, it is also oblivious to the role of motivation in human willing and choosing, leaving us without a hint as to why an organism would want to choose differently under identical conditions. ... [it also] entirely ignores the "human predicament" in which willing occurs - a predicament riddled with reasons, incentives, desires, anxieties, fears and interests that is far removed from the decontextualized atmosphere of metaphysical space (12).

Banja is right: any adequate account of free will, insofar as it is intended to be an account of buman freedom, ought to come to terms with what it means to be free as a human being. And evolutionary accounts of free will are sensitive to aspects of our human nature. They take seriously the relationship between organisms and the world; they understand organisms diachronically and in relationship to their welfare; and often, they shed light on why an organism has acted one way instead of another. Despite the aforesaid merits, it remains unclear whether Banja's evolutionary alternative is sufficiently attuned to our human predicament. That is because a heavy reliance on evolutionary considerations runs the risk of eclipsing practical and social aspects of human life. Such aspects of human life are unlikely to be the products of evolutionary forces, and even if they are, evolutionary accounts are (prima facie) ill-equipped to bring to the fore the embodied, practical, and social dimensions of such 
aspects of human life. Without articulating in some detail how his account of free will accounts for choices that appear to be thoroughly and uniquely social or practical, Banja's understanding of free will seems to share one of the shortcomings of typical libertarian accounts, namely, the inability grasp our human predicament and specifically the context in which our willings and actions occur.

2. The fact that human existence is ineliminably embodied, practical, and social is a key and foundational insight of the phenomenological tradition (Heidegger 1962, Merleau-Ponty 2002). A full discussion of its import and role within the phenomenological tradition is beyond the purposes of this commentary. It suffices to note that according to the phenomenological tradition (or at least, to certain important strands of this tradition), the manner in which situations and objects are disclosed to us depends both on our understanding of their practical, functional, and social significance and on the relationship that they bear to our bodies. In perceiving and navigating the world, not only do we encounter situations already invested with meaning and significance but we also always encounter them in terms of the various action possibilities that they afford us (MerleauPonty 2002, 40-2, 245; 1967, 168). The space of actions, that is, the totality of possible actions that are available to an agent, is thoroughly social, embodied, and practical.

Consider the case of a trained gymnast. A balance beam affords different opportunities to the gymnast than to me. Indeed, the trained gymnast does not merely see the balance beam as an object that can support her weight or as a platform on which she can perform certain movements. She also perceives it as a means to success or to a potential career. She even sees it as an integral part of her life. I, on the contrary, simply fail to see the beam in all of those ways. The example of the gymnast is not unique, special, or in any way recherché. Our skills and sensitivities - be it bodily, social, or practical - transform our world. The world of someone who can read is rather unlike that of someone who cannot: once you acquire the capacity to read, books, road signs, newspaper articles, and evacuation instructions are perceived both as objects and as "calls" for various actions. Similar examples are easy to find: hackers perceive computers and networks as tools for exploitation, computer novices do not; kitchen tools and instruments are perceived primarily as means for cooking by a cook, but not by someone who has never even boiled water.

The above examples highlight the fact that our interactions with the world are already suffused with meaning and significance. More importantly, they also underline the manifest fact that the manner in which situations will be perceived affects the way in which we will act. Stated otherwise: the action possibilities that situations afford us are a function of how such situations are perceived by us. A hacker is both freer and more restrained to act than someone who knows very little about computer programming. Both have the freedom to turn on a computer, but only the former has the freedom to uncover security vulnerabilities - a freedom that depends upon conformity to certain rules (for more on this point see Dahlstrom 2007). Or consider someone who can read. Reading radically 
transforms many objects in her environment and her world is a world rich of possible actions. Books, for instance, are now readable and political leaflets or flyers are infuriating. At the same time however, her choices become, in an important sense, more restricted: she does not open emergency doors, she does not drive into one-way roads, and she minds the gap when stepping out of the subway. Such examples of human conduct call for an explanation.

3. It seems clear that there is a type of freedom - one that is central to our human condition - that is premised on the existence and cultivation of certain abilities. Such abilities are neither clearly innate nor can they be easily explained as the products of evolutionary forces. But if that is the case, then in what way can an evolutionary account help us understand the freedom that results from such abilities? In other words, how could an evolutionary account explain the sense in which agents are free (or constrained) in various thoroughly social and practical situations? Recall that Banja understands freedom to be "a capacity to intend and execute behavior(s) that the organism understands to be in his or her best interests" (12). But the organism's interests are not only biological interests. Banja thus owes us a story as to how his evolutionary understanding of freedom accounts for all the choices that are made available to us. As it stands, Banja's account of freedom appears to be incomplete.

\section{References}

Dahlstrom, D. 2007. The Development of Freedom. Proceedings of the American Catholic Philosophical Association 81: 35 -52.

Heidegger, M. 1962. Being and Time. Translated by John Macquarrie and Edward Robinson. Oxford: Basil Blackwell.

Merleau-Ponty, M. 1967. The Structure of Behavior. Translated by A.L. Fisher. Boston: Beacon Press.

2002. Phenomenology of Perception. Translated by C. Smith. London: Routledge. 